\title{
Antibacterial effects and toxigenesis of Penicillium aurantiogriseum and $P$. viridicatum
}

\author{
Mustapha Khaddor ${ }^{1}$, Rabah Saidi ${ }^{1}$, Anouar Aidoun ${ }^{1}$, Ahmed Lamarti ${ }^{*}$, Abdelrhafour Tantaoui- \\ Elaraki $^{3}$, Mohammed Ezziyyani ${ }^{4}$, Maria-Emilia Candela Castillo ${ }^{4}$ and Alain Badoc ${ }^{5}$ \\ ${ }^{1}$ École Normale Supérieure, BP 229, 93150 Martil, Morocco. \\ 2Département de Biologie, Unité de Biotechnologie et d'Amélioration des plantes,Faculté des Sciences M'hannech II, \\ BP 212, 93002 Tétouan, Morocco. \\ ${ }^{3}$ Sup'Agro (École Supérieure de l'Agro-alimentaire), 22, rue le Câtelet, Belvédère, 20300, Casablanca, Morocco. \\ ${ }^{4}$ Laboratorio de Fisiopatología, Departamento de Biología vegetal, \\ Facultad de Biología, Campus Universitario de Espinardo, 30100 Espinardo, Murcia, Spain. \\ ${ }^{5}$ Laboratoire de Mycologie et Biotechnologie végétale, Faculté des Sciences Pharmaceutiques, Université Victor \\ Segalen Bordeaux 2, 146, rue Léo Saignat, 33076 Bordeaux Cedex, France.
}

Accepted 25 January, 2007

\begin{abstract}
The toxigenesis of one Penicillium aurantiogriseum and one Penicillium viridicatum isolates was investigated. Sterile culture filtrates of both fungi had a clear antibacterial effect only against Bacillus subtilis. The effect on $B$. subtilis varied with amount of filtrate used and temperature. The antibacterial activity of chloroform extracts varied with the nature of media used to grow the fungi. Different mycotoxins were identified in the fungal cultures using thin-layer chromatography. $P$. aurantiogriseum was found to produce penicillic acid, terrestric acid and aurantiamine, while penicillic acid, terrestric acid, brevianamide $A$ and xanthomegnin were produced by $P$. viridicatum.
\end{abstract}

Key words: $P$. aurantiogriseum, $P$. viridicatum, mycotoxins, antibacterial activity.

\section{INTRODUCTION}

Mycotoxins are secondary toxic metabolites elaborated by toxigenic molds in foods. Mycotoxin ingestion represents a real threat to human and animal health. Some of them are very strong carcinogens (Applebaum et al., 1982; Mills et al., 1995). Numerous investigations have reported that various mycotoxins can be produced by Penicillium (Faid and Tantaoui-Elaraki, 1989) including industrially used species when under favourable physicochemical and trophic conditions. Previous works have pointed out that Penicillium aurantiogriseum and

${ }^{*}$ Corresponding author. E-mail: lamarti.ahmed@menara.ma. Phone: (212) 39960569. Fax: (212) 39994500.

Abbreviations: ANIS: Solution of p-anisaldehyde in absolute ethanol - glacial acetic acid -concentrated sulfuric acid; CYA: Czapeck Yeast extract Agar; ENS: École Normale Supérieure; MB: Malt Broth; MEA: Malt Extract Agar; Nm: Nanometre; RF: Migration forehead; TLC: Thin Layer Chromatographie; TYG: Tryptone Yeast extract Glucose; YES: Yeast Extract Sucrose.
Penicillium viridicatum are among major Penicillium species represented in foods such as olives, cereal grains and derivatives (Maouni, 1997; Mills et al., 1995; Sebti and Tantaoui-Elaraki, 1994; Tantaoui-Elaraki et al., 1990). Furthermore, both species have shown more resistance to antifungal agents (sorbic and benzoic acids, calcium propionate, cinnamon extract) than other fungi (Sebti and Tantaoui-Elaraki, 1994).

The aims of this work were to determine whether culture sterile filtrates and extracts of the two species are toxic to selected bacteria and to identify the toxic metabolites produced, if any.

\section{MATERIALS AND METHODS}

\section{Microorganisms}

P. aurantiogriseum was isolated from "Pastilla papers" in a previous work (Sebti and Tantaoui-Elaraki, 1994), and its identification was confirmed by the "Institut Scientifique de la Santé Publique Louis Pasteur", Brussels, Belgium. 
Table 1. Culture media used in this study.

\begin{tabular}{|l|l|}
\hline Medium & Composition (for $1 \mathrm{I}$ distilled water) \\
\hline MB & $130 \mathrm{~g}$ malt extract \\
MEA & $20 \mathrm{~g}$ malt extract, $1 \mathrm{~g}$ peptone, $20 \mathrm{~g}$ glucose, $15 \mathrm{~g}$ agar \\
\hline CYA & $\begin{array}{l}10 \mathrm{~mL} \text { concentrated Czapeck, } 1 \mathrm{~g} \mathrm{~K}_{2} \mathrm{HPO}_{4}, 5 \mathrm{~g} \text { yeast extract, } 30 \mathrm{~g} \text { sucrose, } 15 \\
\text { (concentrated Czapeck: } 30 \mathrm{~g} \mathrm{NaNO}_{3}, 5 \mathrm{~g} \mathrm{KCl}, 5 \mathrm{~g} \mathrm{MgSO}_{4}, 7 \mathrm{H}_{2} \mathrm{O}, 0.1 \mathrm{~g} \\
\text { FeSO }\end{array}, 7 \mathrm{H}_{2} \mathrm{O}, 1000 \mathrm{ml}$ distilled water) \\
\hline YES broth & $20 \mathrm{~g}$ yeast extract, $100 \mathrm{~g}$ sucrose \\
\hline YES agar & $20 \mathrm{~g}$ yeast extract, $100 \mathrm{~g}$ sucrose, $15 \mathrm{~g}$ agar \\
\hline TYG & $3 \mathrm{~g}$ tryptone, $3 \mathrm{~g}$ yeast extract, $3 \mathrm{~g}$ glucose, $1 \mathrm{~g} \mathrm{~K}_{2} \mathrm{HPO}_{4}, 15 \mathrm{~g}$ agar \\
\hline
\end{tabular}

$P$. viridicatum was isolated from wheat at the "École Normale Supérieure" (ENS) Food Microbiology Laboratory, Tétouan, Morocco. Four of the bacteria used were furnished by the ENS Food Microbiology Laboratory collection: Bacillus subtilis, Bacillus megaterium, Escherichia coli and Lactococcus (L.) lactis subsp. diacetylactis (hereafter called $L$. diacetylactis). The fifth one, a non pathogenic mutant of Salmonella typhimurium TA 100, was given by the Toxigenetics Laboratory, Biology Department, Faculty of Sciences, Tétouan, Morocco.

\section{Fungal cultures}

For preparation of fungal inocula, Penicillium strains were cultivated in petri dishes on malt extract agar (MEA) and incubated 5 days at $25^{\circ} \mathrm{C}$. Then the spores were collected in sterilized $0.1 \%$ Tween 80 water solution. After enumeration of the spores in the suspension by hematimetry, their numbers were adjusted to $10^{7}$ spores $/ \mathrm{ml}$ by dilution in $0.1 \%$ Tween solution. The fungi were cultivated in flasks containing $25 \mathrm{ml}$ MEA, Malt Broth (MB), Czapeck Yeast extract Agar (CYA), Yeast Extract Sucrose (YES) broth or YES agar (Table 1). Each flask was inoculated with $2 \mathrm{ml}$ fungal inoculum and incubated $10 \mathrm{~d}$ at $25^{\circ} \mathrm{C}$.

\section{Preparation of culture filtrates and extracts}

In order to underline fungal toxigenesis, sterile culture filtrates and extracts were prepared. At the end of incubation period on YES broth, $5 \mathrm{ml}$ of liquid culture were taken and filtered first through Whatman paper to remove the mycelium, and then through $0.45 \mu \mathrm{m}$ millipore membrane for sterilization. The sterile culture filtrates were used for antibacterial activity tests.

It is well established that mold toxigenesis is widely influenced by numerous environmental conditions including nutritional parameters (Hâggblom and Ghosh, 1985). Same fungus may produce a given mycotoxin in a given medium while it may synthesize another toxic metabolite under different nutritional conditions. Therefore, known mycotoxins of the two Penicillium were searched in various media (MEA, MB, CYA, YES broth and YES agar). At the end of incubation period, $25 \mathrm{ml}$ chloroform was added to each fungal culture flask. After shaking $10 \mathrm{~min}$, the chloroformic phase was recovered, filtered through anhydrous sodium sulfate to remove aqueous phase droplets, and concentrated with a rotavapor. The concentrate was dried under nitrogen flow and $1 \mathrm{ml}$ ethanol was added to dissolve the dry extract. Half this volume was dried again and redissolved in $1 \mathrm{ml}$ distilled water. This aqueous solution was sterilized by millipore filtration to be tested for antibacterial activity. The other half was used to search for mycotoxins by thin layer chromatography.

\section{Identification and separation of the mycotoxins by thin layer chromatography (TLC)}

Kieselguhr $60 \mathrm{~F}_{254}$ TLC plates were used, according to the technique described by Mills et al. (1995). Standard mycotoxins used for reference of migration forehead (Rf) were patulin, citrinin and ochratoxine A. $10 \mu \mathrm{L}$ of each ethanol extract, and $10 \mu \mathrm{L}$ of standard solutions $(1 \mathrm{mg} / \mathrm{ml})$ were spotted on TLC plates. The elution systems used were as follows: toluene - ethyl acetate formic acid (5/4/1, v/v/v) and chloroform - acetone - 2-propanol $(85 / 15 / 20, v / v / v)$. The plates were developed under darkness and examined at daylight, 365 and $254 \mathrm{~nm}$. Spots with Rf different from standard on either elution systems were not considered. Confirmation of toxins was performed as follows: spraying of the spots by ANIS: $0.5 \%(\mathrm{v} / \mathrm{v})$ solution of $\mathrm{p}$-anisaldehyde in absolute ethanol - glacial acetic acid -concentrated sulfuric acid (17/2/1, $\mathrm{v} / \mathrm{v} / \mathrm{v}$ ), heating $8 \mathrm{~min}$ at $120^{\circ} \mathrm{C}$. Some toxins specifically react with ANIS at this temperature, leading to characteristic colours under daylight, i.e. lilac blue for penicillic acid, yellow for terrestric acid and grey for aurantiamine. On TLC plates none treated with ANIS, areas corresponding to identify toxins were scratched and recovered with chloroform. The chloroform was completely evaporated and the residue redissolved in ethanol. Half the ethanol volume was used to confirm mycotoxin purity on a new TLC plate with ANIS. The other half was evaporated again, redissolved in water and millipore filtered in order to be used for antibacterial activity.

\section{Evaluation of antibacterial activity}

B. subtilis was first reactivated by cultivation on TYG and incubation at $37^{\circ} \mathrm{C}$ for $24 \mathrm{~h}$. Suspensions containing $10^{6} \mathrm{cells} / \mathrm{ml}$ in sterile distilled water was used for inocula. Petri dishes $(\varnothing: 90$ $\mathrm{mm}$ ) containing Tryptone Yeast extract Glucose (TYG) were surface inoculated with $0.2 \mathrm{ml}$ of bacterial inocula. $15 \mathrm{~min}$ after inoculation, 4 cavities of $6 \mathrm{~mm}$ diameter were dug out in the agar medium. Three of them were filled with $0.1 \mathrm{ml}$ of culture sterile filtrate, aqueous extract or extracted mycotoxin and the fourth one was used as control. After $24 \mathrm{~h}$ incubation at $37^{\circ} \mathrm{C}$ or $30^{\circ} \mathrm{C}$ to avoid too quick bacterial growth, the antibacterial effect was determined by measurement of the inhibition zone diameters. The effects of filtrate quantities varying from 0.02 to $0.1 \mathrm{ml}$ poured into the cavities and of temperature $\left(17,25,30,34\right.$ and $\left.37^{\circ} \mathrm{C}\right)$ were also tested on the antibacterial activity. 
Table 2. Toxicity of Penicillium aurantiogriseum and P.viridicatum culture filtrates to different bacteria (average of 3 determinations, 3 replicates).

\begin{tabular}{|l|c|c|}
\hline \multirow{2}{*}{\multicolumn{1}{|c|}{ The bacteria $^{\star \star}$}} & \multicolumn{2}{|c|}{ Diameters of inhibition zones (mm) } \\
\cline { 2 - 3 } & $\boldsymbol{P}$. aurantiogriseum & P. viridicatum $^{\star}$ \\
\hline Escherichia coli & 00 & 00 \\
Bacillus megaterium & 00 & 00 \\
Bacillus subtilis & 13 & 20 \\
Lactococcus diacetylactis & 00 & 00 \\
Salmonella typhimurium & 10 & 00 \\
\hline
\end{tabular}

${ }^{*}$ Fungal culture on YES Broth for $10 \mathrm{~d}$ at $25^{\circ} \mathrm{C}$; filtration through Millipore membrane; $0.1 \mathrm{~mL}$ of filtrate used.

**Bacteria cultivated on TYG, incubation at $37^{\circ} \mathrm{C}$ for $24 \mathrm{~h}$.

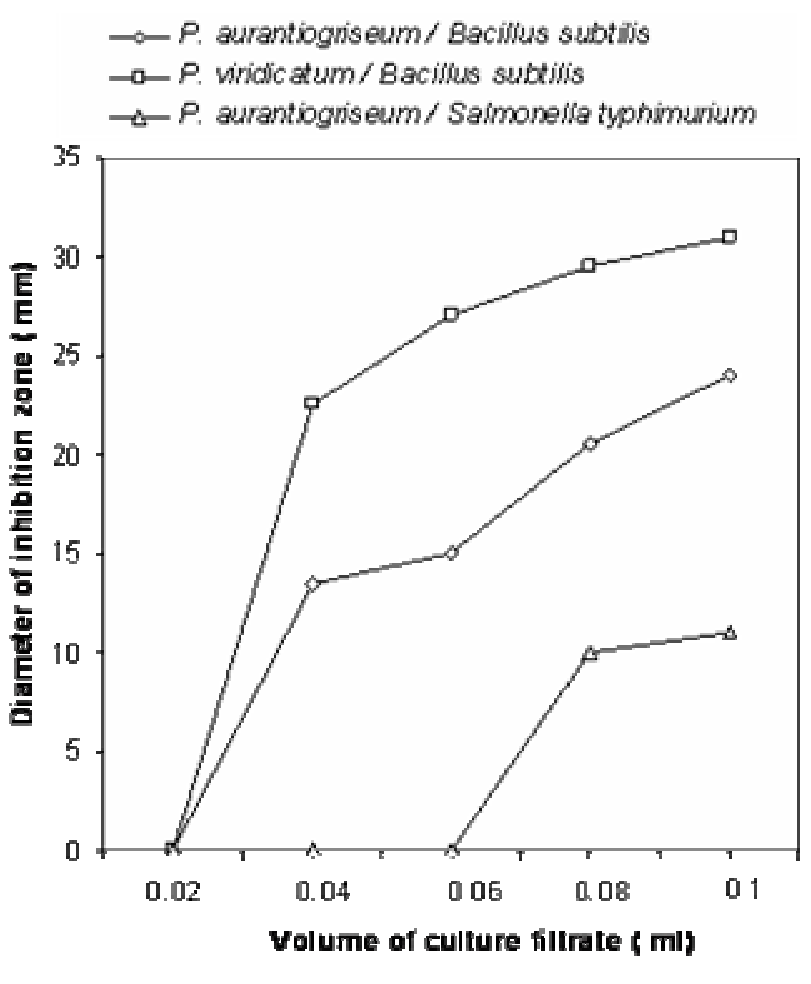

Figure 1. Effect of the volume of fungal culture filtrate on the antibacterial activity after $24 \mathrm{~h}$ at $30^{\circ} \mathrm{C}$ (three replicates).

\section{RESULTS AND DISCUSSION}

\section{Effect of bacterial species}

B. subtilis was the most sensitive to both $P$. aurantiogriseum and $P$. viridicatum culture filtrates, with inhibition zone diameters of 13 and $20 \mathrm{~mm}$, respectively (Table 2). S. typhimurium was only slightly sensitive to $P$. aurantiogriseum filtrate $(10 \mathrm{~mm})$. All other bacteria were totally insensitive to both filtrates. B. megaterium has been reported to be sensitive to culture filtrates of Penicullium italicum and Penicilium digitatum (Faid and Tantaoui-Elaraki, 1989) and more than 12 other different Penicillium species (Carlton et al., 1976). Among 154 Penicillium isolates tested by Samane et al. (1991), about $63 \%$ were shown to have culture filtrates toxic or very toxic to $B$. megaterium. However, none of the Penicillia involved belonged to the species $P$. aurantiogriseum and $P$. viridicatum. Both sensitive and insensitive bacterial groups included at least one Gram positive and one Gram negative species. Thus, there seems to be no influence of the cell wall structure on the sensitivity of the bacteria to the fungal culture filtrates studied.

\section{Effects of filtrate volume and temperature}

The antibacterial effect on $B$. subtilis and S. typhimurium increased together with the amount of filtrate used (Figure 1). All other bacteria remained insensitive independently of the amount of culture filtrate poured. The effect of incubation temperature on the antibacterial activity of fungal culture filtrates was determined with $0.1 \mathrm{ml}$ filtrate on $B$. subtilis (Figure 2). The diameter of inhibition zone slightly varied between 17 and $34^{\circ} \mathrm{C}$. At $37^{\circ} \mathrm{C}$, the inhibitory effect decreased significantly for both fungal species, probably because of an intense metabolism of $B$. subtilis at its optimal growth temperature.

\section{Comparative effect of culture filtrates and extracts}

The antibacterial effects observed with fungal YES broth filtrates were higher than those produced by the corresponding YES broth extracts. After $24 \mathrm{~h}$ incubation at $37^{\circ} \mathrm{C}$, average inhibition zone diameters measured were 20.1 and $13.3 \mathrm{~mm}$, respectively, with $P$. aurantiogriseum, and 30.3 and $24 \mathrm{~mm}$, respectively, with $P$. viridicatum. The active principles could not be sufficiently soluble in chloroform, ethanol and water to remain totally in the final extract. 
Table 3. Toxicity of culture filtrates $(0.1 \mathrm{~mL})$ of two Penicillium obtained after cultivation on three media 10 days at $25^{\circ} \mathrm{C}$ to B. subtilis cultivated $24 \mathrm{~h}$ at $30^{\circ} \mathrm{C}$ on TYG (average of 3 determinations, 3 replicates).

\begin{tabular}{|l|c|c|}
\hline \multirow{2}{*}{$\begin{array}{c}\text { Fungal culture } \\
\text { media }\end{array}$} & \multicolumn{2}{|c|}{ Diameters of inhibition zones $(\mathbf{m m})$} \\
\cline { 2 - 3 } & P. aurantiogriseum & P. viridicatum \\
\hline MEA & 11.5 & 20.3 \\
CYA & 14.5 & 13.3 \\
YES agar & 13.3 & 24.0 \\
\hline
\end{tabular}

\section{Effect of culture media on antibacterial activity of chloroformic extracts}

For $P$. aurantiogriseum, the highest inhibition zone diameter was observed with CYA culture extract (14.5 $\mathrm{mm}$ ) while MB medium was associated with the lowest effect $(11.5 \mathrm{~mm})$ (Table 3). However, for $P$. viridicatum, YES culture extract was the most efficient $(24 \mathrm{~mm})$ and CYA culture extract the weakest $(13.3 \mathrm{~mm})$.

\section{Identification of mycotoxins}

Three different toxins were identified in $P$. aurantiogriseum cultures: penicillic acid, terrestric acid and aurantiamine. They have been reported by other authors (Mills et al., 1995), together with many other mycotoxins (Kozakiewicz, 1992a). In this work, penicillic acid and aurantiamine were detected in YES Agar, MB and CYA, while terrestric acid was found together with penicillic acid in MEA and alone in YES Broth. Mills et al. (1995) have also found penicillic acid and aurantiamine in CYA. However, they have detected terrestric acid in YES agar. Four mycotoxins were found to be produced by $P$. viridicatum: penicillic acid, terrestric acid, brevianamide $A$ and xanthomegnin.

In MEA, all four toxins were synthetized, while terrestric acid alone was detected in YES broth and penicillic acid in YES agar. None of the four metabolites was found in CYA. Previous works have reported penicillic acid (Kozakiewicz, 1992b; Mills et al., 1995), brevianamide A (Kozakiewicz, 1992b; Mills et al., 1995; Müller and Boley, 1993) and xanthomegnin (Carlton et al., 1976; Kozakiewicz, 1992b; Mills et al., 1995; Müller and Boley, 1993) to be produced by $P$. viridicatum. Using CYA, Mills et al. have found both brevianamide A and xanthomegnin, together with other mycotoxins: penicillic acid, penitrem $\mathrm{A}$, vioxanthin and viomellein. $P$. viridicatum is known to produce also ochratoxin $A$, a metabolite toxic to many animals (Hâggblom and Ghosh, 1985).

\section{Effect of toxins purified by TLC}

Three different substances taken from TLC plates and redissolved in water were tested for antibacterial activity

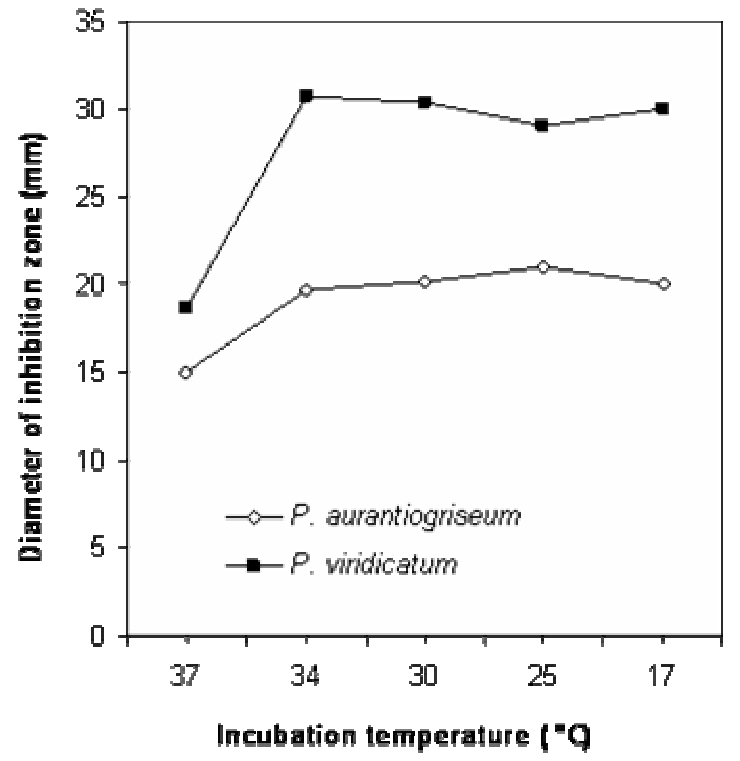

Figure 2. Effect of incubation temperature for 24 $\mathrm{h}$ on the toxicity of two Penicillium culture filtrates on Bacillus subtilis (three replicates).

on $B$. subtilis incubated $24 \mathrm{~h}$ at $30^{\circ} \mathrm{C}$. According to their respective Rfs, those substances were penicillic acid, terrestric acid and aurantiamine.

\section{REFERENCES}

Applebaum RS, Brackett R, Wiseman D, Marth EH (1982). Aflatoxin : toxicity to dairy cattle and occurrence in milk and milk products. J. Food Protect. 45: 752-777.

Carlton WW, Stack ME, Eppley RM (1976). Hepatic alterations produced in mice by xanthomegnin and viomellein, metabolites of Penicillium viridicatum. Toxicol. Appl. Pharmacol. 38: 455-459.

Faid M, Tantaoui-Elaraki A (1989). Production of toxic metabolites by Penicillium italicum and $P$. digitatum isolated from citrus fruits. J. Food Protect. 52: 194-197.

Hâggblom PE, Ghosh J (1985). Posthawest production of ochratoxin A by Aspergillus ochraceus and Penicillium viridicatum in barley with different protein levels. Appl. Environ. Microbiol. 49: 787-790.

Kozakiewicz Z (1992a). IMI descriptions of fungi and bacteria. No. 1101. Penicillium aurantiogriseum. Mycopathologia. 117: 165-166.

Kozakiewicz Z (1992b). IMI descriptions of fungi and bacteria. No. 1110. Penicillium viridicatum. Mycopathologia. 117: 183-184.

Maouni A (1997). Recherche des Penicillium contaminant les olives de table. DEA dissertation, University Abdelmalek Essaidi, Faculty of the Sciences, Tétouan, Morocco.

Mills JT, Frisvad JC, Seifert KA, Abramson D (1995). Identification of nephrotoxic Penicillium species from cereal grains. Mycot. Res. 11: 25-36.

Mills JT, Seifert KA, Frisvad JC, Abramson D (1995). Nephrotoxigenic Penicillium species occurring on farm-stored cereal grains in western Canada. Mycopathologia. 130: 23-28.

Müller HM, Boley A (1993). Studies on the refrigerated storage of wheat (Triticum aestivum). 2. Ergosterol, xanthomegnin, viomellein and brevianamide $A$ after inoculation with Penicillium viridicatum. Zentralblatt für Mikrobiologie. 148: 419-431.

Samane S, Tantaoui-Elaraki A, Essadaoui M (1991). Mycoflore of Moroccan " Greek style" black olives. II. Toxigenesis. MicrobiologieAliments-Nutrition. 9: 335-352. 
Sebti F, Tantaoui-Elarraki A (1994). In vitro inhibition of fungi isolated from "Pastilla» papers by organic acids and cinnamon. Lebensmittel Wissenschaft and Technologie. 27: 370-374.

Tantaoui-Elaraki A, Samane S, Roquebert MF (1990). Mycoflora of Moroccan Greek Style Black Olives. I-Inventory. MicrobiologieAliments-Nutrition. 8: 257-261. 